\title{
Basic Research of Cultural Factor in Improved Product Design
}$$
\text { Jianqiu Mao, a }{ }^{\text {* }} \text {, Shuguang Sang }{ }^{2, b}
$$ \\ ${ }^{1}$ Address: 336 West Road, Nan XinZhuang, College of Mechanical Engineering, University of Jinan, \\ Shandong, China \\ ${ }^{2}$ Address: 336 West Road, Nan XinZhuang, College of Mechanical Engineering, University of Jinan, \\ Shandong, China

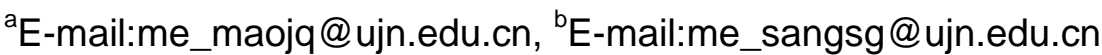

Keywords: Improved design; Culture gene; Functionalism; Innovative approach

\begin{abstract}
The tide of history irreversibly coerced various cultural styles, under the rapid push of technology, batches of unprecedented products are created, the style of internationalism is popular all over the world, making each civilization more awakening of the meaning of their existence. Today, as the industrial civilization and informatization are highly developed, the cultural characteristics of a product, especially the objective profit brought by products with high cultural added value make them become each brand and even the attention of all countries. Through some malpractice and design case analysis of local design, this article discussed the main idea of how the traditional creation thinking and skills transform successfully to modern design in order to inspire modern design. Historically, a tribute to our traditional culture maybe the only way to the renaissance of Chinese design.
\end{abstract}

\section{Introduction}

The literary quotation of "Chang Kuo-lao riding a donkey" is known by everyone, buy why did Chang Kuo-lao ride a donkey? There is a legend, after Chang Kuo-lao was enlightened, he found that many things' developing forward may not be good thing, therefore, he expressed this profound philosophy by performance art of " riding a donkey backwards" to alert the world, unfortunately, few people can understand, whether the legend is true or false, we have no way to investigate its authenticity. But this way of observing the world with dialectical and unique transformation perspective is none other than the core of Taoism, which happens to coincide with the Japanese design master - Yan Yuan Zai after two thousand years:" The acquisition of creativity is not necessarily standing in front of the times, if we can see long-term enough, perhaps the source of creation is still hidden behind us. 【1】 -- Yan Yuan Zai

\section{The cultural attributes levels of products}

Culture can be generalized to three levels, as shown in Fig. 1: 


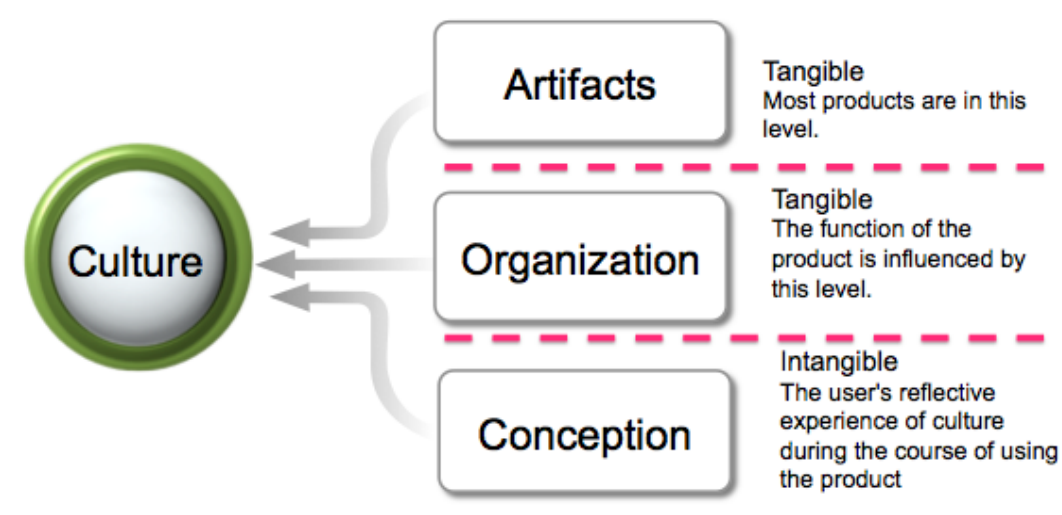

Fig. 1 the cultural attributes levels of products

Level of artifacts. The main performance is tools for production and living, what kind of tools and utensils the state or society uses for production and living. For example, Chinese people use chopsticks, Westerners use knives and forks, Indians use hands.

Level of organization. This level mainly includes how individuals are organized in this society so that single individual can combine, live together in a society and how they interact with each other. It contains a lot of contents, such as political organization, religious organization, production organization, state machinery and so on; popularity of products is also dependent on different organizational structure. Reflected in the products, the product functional requirements were caused by differences of users' cognition habits, this level is non-dominant, it is required of observation and experience.

Level of conception . How people think, what they can accept? What they cannot accept? What is good? What is wrong? Between good and bad, values and behavior selection standards of various societies are not the same. Just like there is no profound aristocratic tradition in Northern European, while this is just the unique, natural and plain Nordic-style humanity foundation in product design history. Reflected in the products, it is users' introspection experience of the products, this level is also non-dominant; it is required of profound analysis.

Three levels are indivisible, they are an organic whole, the products are always covered in culture.

\section{Flaw in contemporary Chinese product design - breakage of cultural gene}

Looking around in China, phenomenon of similar products is spectacular, for tourist souvenirs or other things, they are all in the same key or they are the intact copies of cultural relics, the Chinese culture is broad and profound, through time and space of thousands of years, the great Tao is of course everlasting, but its substance reflection is bound to change, it is an indisputable fact. For most Chinese products, because of the thorough understanding for culture and function, the modelling and design of the products are superficial, it is difficult to reproduce the cultural spirit connotation, resulting in products' out of line with culture itself.

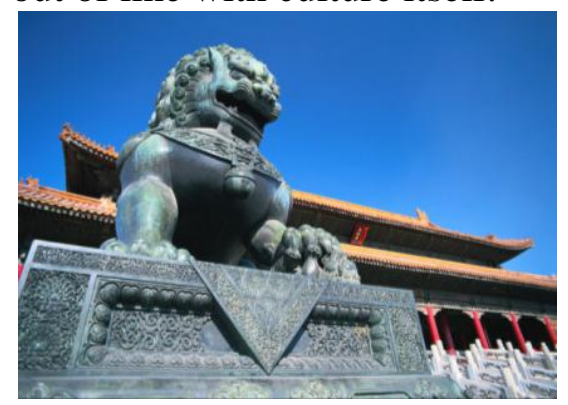

Fig. 2 Stone lion statue of the Imperial Palace (Ming Dynasty)

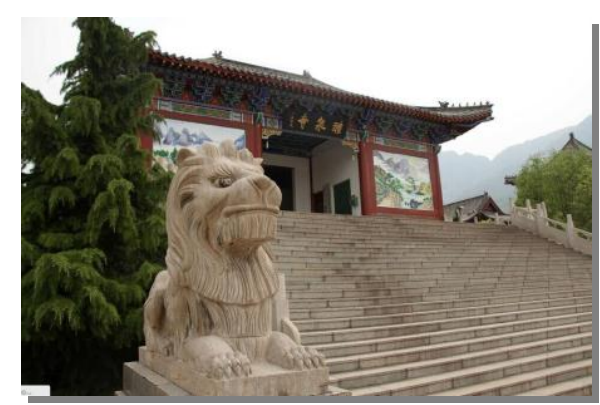

Fig. 3 Statue similar to Lion King Simba before a temple in some place in Shandong (2014) 
Disappearance of traditional handicraft. The Chinese lion is more enjoyable (Fig. 1), there are more decorations and exaggeration in it, full of tension and unlimited possibilities, but look at this nondescript modern lion image (Fig. 2), people can not help worrying about the

creation ability of the Chinese people. When our traditional skill of art creation declines to such condition, there is no tolerance and charm to speak of, even the ancient-imitating craft and techniques are not deserving artistic criticism, how we can innovate? When the tool is more advanced, the traditional skill is gradually vanishing.
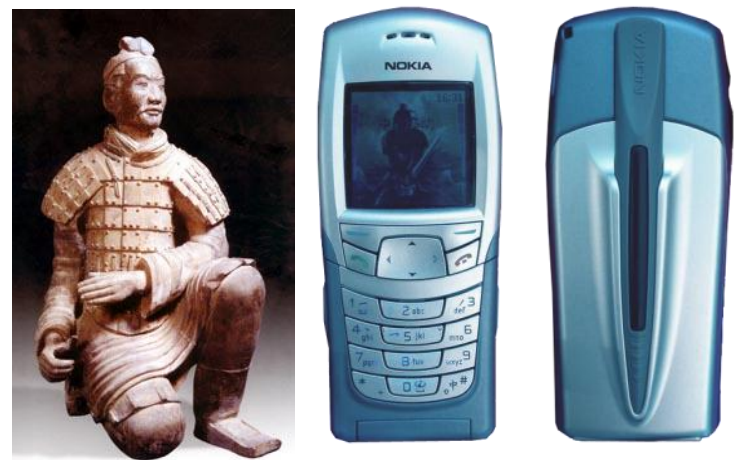

Fig. 4 Nokia 6820 mobile phone of which the originality is from Terra-Cotta Warriors

Design of modern product can not naturally integrate traditional cultural elements. In 2004, for users' needs of the Chinese market, Nokia explored the Chinese traditional culture elements, the development and design originality of 6820 model mobile phone is coming from Terra-Cotta Warriors, it retained its own traditional style and also contained the invisible oriental style, modern product design and traditional culture was combined naturally, reasonably and perfectly.
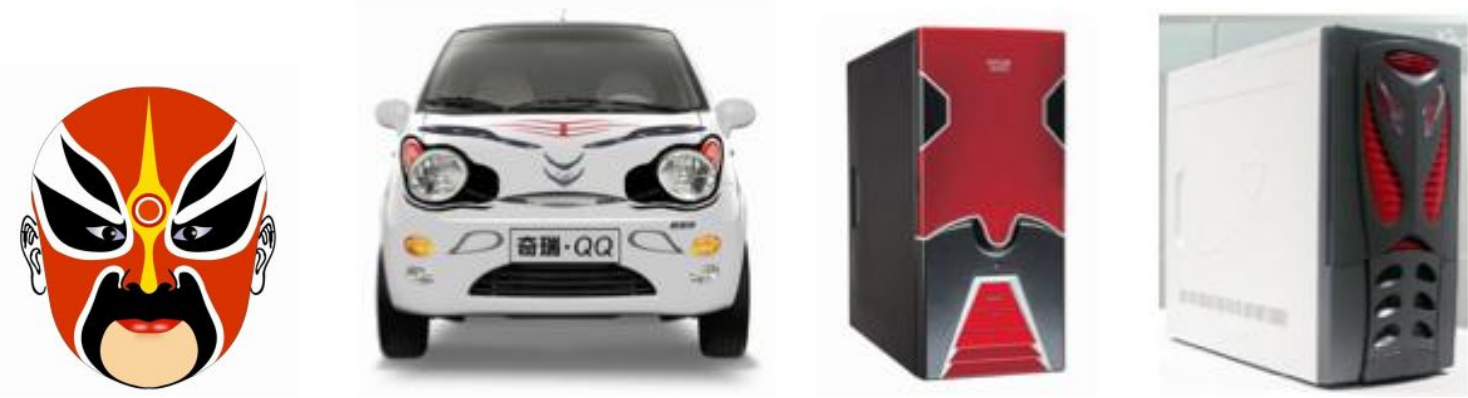

Fig. 5 Chinese local designs with the originality of facial makeup

In the field of product design, there are also such examples, the facial makeup is a visual essence of highly concentrated Chinese culture, but the above design (see Fig. 4) did not attract people's interest, the reason is this design ignores product's requirement for simplicity, simply went to the side of the styleism. "A door-hinge is never worm-eaten, running water never becomes putrid", unfortunately, there was a fault in modern times in the spread of our Chinese culture, although we have great publicity for revival of Chinese culture, the original ecological life environment as well as change in social ethical environment made these "revival" more or less superficial, traditional humanistic spirit and aesthetic psychology have suffered to hit, making a generation or even several generations have a doubt and unconfidence for our great national culture, this made people feel bad, what is reflected in the field of material culture most obviously is that the degradation of aesthetic standards caused product cheap and vulgar, many cultural products are vulgar or shoddy, or blindly pursuiting for expensiveness and luxury. 


\section{Good functionality is the foundation for emotional design}

Design case of Chinese chair. Traditional utensils have strong handicraft feature, with lovingly and warm humanity breath that machinery age products did not have, there is no so-called ergonomics and mechanics of materials, each artisan can use a knife or an ax with facility, uncanny workmanship is about to describe such skills.

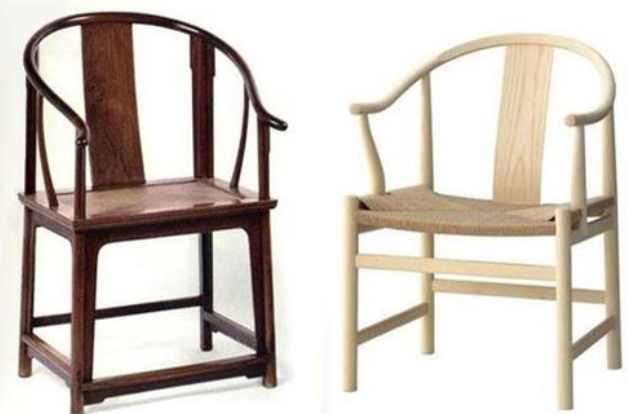

Fig. 6 Old-fashioned wooden armchair (Ming Dynasty) on the left, and "Chinese chair" designed by Hans Wagner, on the right (1945)

The "Chinese chair" designed by world-renowned Danish chair design master, interpreting the modern transformation of Ming-style furniture to the point. "Too like is the kitsch, not like deceiving, wonderful is in between like and not like" said by Mr. Qi Baishi, this sentence just hit the design secret of Hans Wagner, the contour of Ming-style furniture loomingly appeared on the "China chair", the smell is like a wisp of subtle fragrance of green tea, which is totally different with hot and full-bodied coffee aroma, the warm of culture arises spontaneously, perhaps this is the true meaning of heritage and innovation. Before ergonomics flourished, with perennial experience, Hans knew the importance of each size of chair for human comfort, and explained with the most concise and perfect form.

Hans himself also said: I never set to create a style, it is a continuous purification process. For me, it is a process of continuous simplify."Concentrate on one thing, as skillful as Paoding dissected a cattle, or like a skillful oil selling old man, as an important founder of modern "organic functionalism", Wagner still sticks to the tradition as a carpenter and handicraftsman - he has never been controlled by modern new technology and new materials as well as the ever-changing design style, he adhered to the basic structure and wood, with his superb technology, Hans - Wagner created miracles one after another in modern design history, this is just the sonorous voice of handicraft of "technology is almost the great Tao" in modern design. Before ergonomics was popular, Wagner had been already keenly aware of how we can make people more comfortable, longer sitting. "People body is never still. A good chair should be able to allow people to freely adjust the position on it, and maintain long-term blood flowing." There is a often quoted saying by this prolific designer,"the design and manufacturing of a chair is truly completed until the day someone sitting on it".

Improved road of Pandora jewelry. Form follows function, if this famous modern design theory is put into the design of the ancient civil artifacts, it is still an applicable law, whether the using function of an item will continue determines whether it can survive in modern society, while form is necessarily limited by functionality. Traditional skills are the basis of traditional Chinese creation, design theory and philosophy are naturally contained in it, it is no use to apply for many intangible cultural heritage, the key is whether it is inherited in real using environment, it can only solve temporary worry.

Pandora jewelry is a very successful brand case on its way from traditional to modern, it is a jewelry brand founded in 1982 by a Danish couple, the couple originally often imported jewelry from Thailand for trading, later they founded their own jewelry brand and did independent design. 

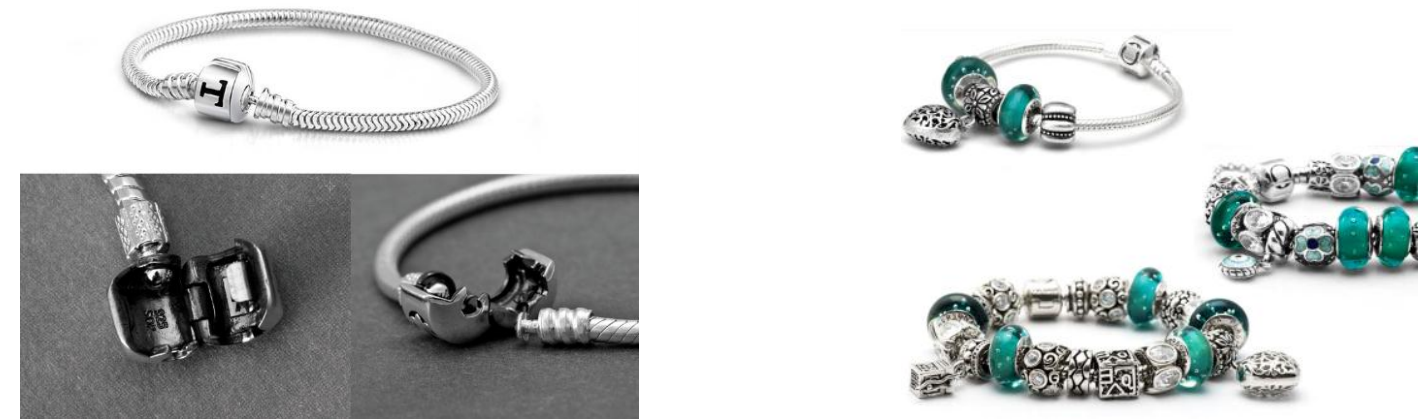

Fig. 7 Pandora foundational adjustable bracelet Fig. 8 Each of modular designed bead can be removed individually

The meaning of Pandora jewelry is from Greek mythology "Pandora's Box", meaning the "hope", it leads the traditional Thai beaded jewelry craft towards modern times, the modular design of bracelets and beads makes consumers combine freely, each bead has its own story, consumers can design bracelet belong to themselves, which is just a reflection of user participation in the design, it is also a typical modular product design, which meets the modern consumer's pursuit of individuality and participation, promote the traditional Thai hand-beaded jewelry to the world by modernized style, this is an excellent case of the good features heritage.

\section{Summary}

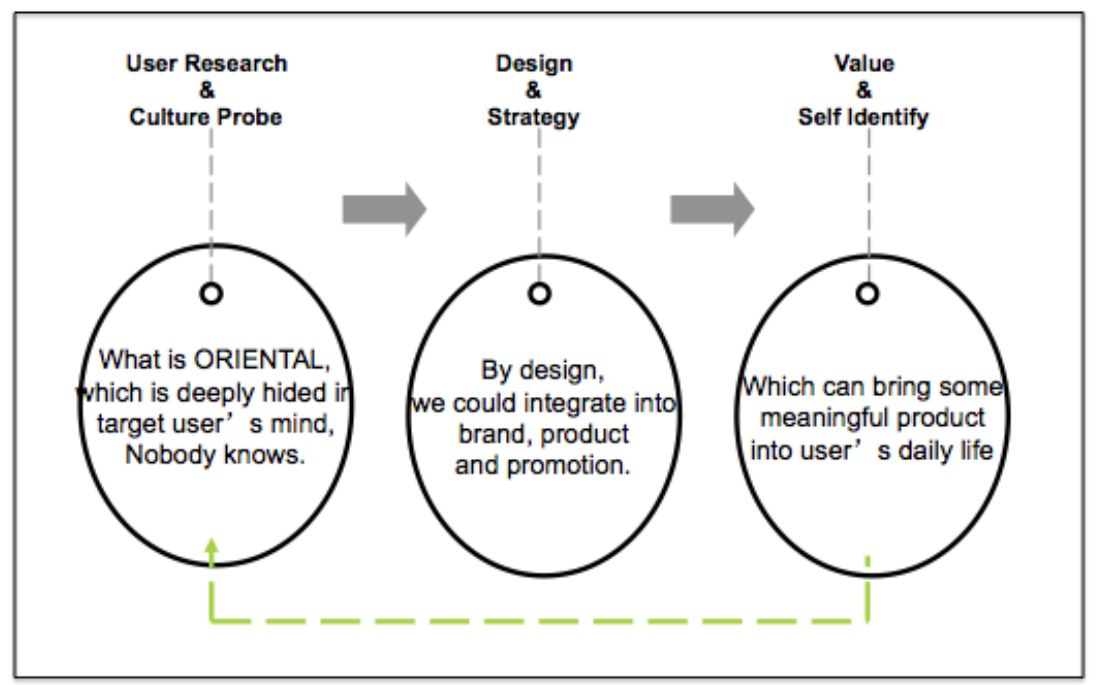

Fig. 9 the innovative development flowchart of improving product cultural value

In design, there are some forms beyond the functions, we can understand them as decorative, aesthetic, artistic, but we can also understand these forms in a broader view of humanity. Effective heritance of traditional crafts and function of promoting the new, or to help cultural products get lasting vitality, in learning the tradition, to make traditional Chinese culture creations shine in modern society, this is the mission of our generation of design .

\section{References}

[1] Desmet, P.M.A., Overbeeke, C.J., Tax, S.J.E.T. Designing products with added emotional value: development and application of an approach for research through design. The Design Journal, 2001, 4(1), 32-47.

[2] Desmet, P.M.A., \& Hekkert, P. (2002). The basis of product emotions. In: W. Green and P. Jordan (Eds.), Pleasure with Products, beyond usability (60-68). London: Taylor \& Francis. 
[3] Green, W.S. and Jordan, P.W. (eds.). Pleasure with Products: Beyond Usability. London, Taylor \& Francis, 2001.

[4] Desmet, P.M.A. (2003). A multilayered model of product emotions. The Design Journal. In press.

[5] Beck,E.,Christiansen,M,Kjeldskov, J., Kolve, N. and Stage, J. Experimental Evaluation of Techniques for Usability Testing of Mobile Systems in a Laboratory Setting. In Proceedings of OzCHI. (2003).

[6] Desmet, P.M.A., Porcelijn, R., \& van Dijk, M.B. (2005). HOW to design WOW?, Introducing a layered-emotional approach. In: S. Wensveen (ed.), Proceedings of The International Conference on Designing Pleasurable Products and Interfaces, October 24-27.

[7] Weerdesteijn, J.M.W., Gielen, M.A. and Desmet, P.M.A.Playing with body language and emtions, Understanding emotions and exploring body language with the help of "emotion objects", In press.

[8] Desmet, P.M.A. Designing Emotions. Unpublished doctoral thesis. ISBN 90-9015877-4 , 2002

[9] Hekkert, P., \& van Dijk, M.B. Designing from context: Foundations and applications of the ViP approach. In P. Lloyd \& H. Christiaans (eds.), Designing in Context: Proceedings of Design Thinking Research Symposium 5 (pp. 383-394). Delft, DUP Science, 2001.

[10] Green, W.S. and Jordan, P.W. (eds.). Pleasure with Products: Beyond Usability. London, Taylor \& Francis,2001. 